\title{
Vitamin D Deficiency Is Associated with Erectile Dysfunction in Men with Type 2 Diabetes
}

\author{
Shahjada Selim ${ }^{1,}$, Hafiza Lona ${ }^{2}$ \\ ${ }^{1}$ Department of Endocrinology, Bangabandhu Sheikh Mujib Medical University, Dhaka, Bangladesh \\ ${ }^{2}$ Department of Biochemistry, Medical College for Women's, Uttara, Dhaka, Bangladesh
}

Email address:

selimshahjada@gmail.com (S. Selim)

*Corresponding author

\section{To cite this article:}

Shahjada Selim, Hafiza Lona. Vitamin D Deficiency Is Associated with Erectile Dysfunction in Men with Type 2 Diabetes. International Journal of Diabetes and Endocrinology. Vol. 5, No. 4, 2020, pp. 77-82. doi: 10.11648/j.ijde.20200504.15

Received: December 2, 2020; Accepted: December 17, 2020; Published: December 22, 2020

\begin{abstract}
Background and aims: Evidence suggests strong a relationship of vitamin D deficiency (VDD) with erectile dysfunction (ED) in men. The prevalence and long-term complications of diabetes are being recognize more increasingly that has the possible association again with VDD. Thus, the study aimed to find out the association between VDD and ED among Bangladeshi adult men with type 2 diabetes. Materials \& Methods: This nested case-control study recruited 2860 adult patients with type 2 diabetes mellitus (T2DM) who had ED (aging between $30-69$ years). The patients who found to have normal vitamin D level, were taken as control and those had VDD, were categorized as the case. The study was conducted in eight diabetes care centers of Bangladesh. Socio-demographic and personal information of the respondents were collected by faceto-face interview and disease-specific data were recorded from the patient's diabetic record book. The bodyweight, height, waist circumference, hip circumference and blood pressure were also recorded. Fasting blood sample was collected to estimate serum levels of vitamin D, glucose, and free testosterone. Results: The diabetes patients with ED had more severe VDD [(25 $\mathrm{OH}) \mathrm{D}<10 \mathrm{ng} / \mathrm{mL}$ ] than the controls $(61.28 \%$ and $62.16 \%$, respectively). The more severe form of ED found in the lower levels of serum vitamin D. A linear relationship of VDD was found with ED [OR 2.83, CI 2.36, 3.97] in multivariate logistic regression analysis. Conclusions: Vitamin D deficiency is an independent risk factor of ED in men with type 2 diabetes mellitus and severity of ED is linearly associated with the degree of deficiency of vitamin D.
\end{abstract}

Keywords: Vitamin D, Erectile Dysfunction, Diabetes Mellitus

\section{Introduction}

Men with type 1 diabetes (T1DM) and type 2 diabetes (T2DM) are at increased risk of ED and of the adult men might have it [1,2]. The Massachusetts male aging study [3], found men with diabetes to have a three-fold increased probability of having ED comparing with men without diabetes; the ageadjusted risk of ED was double in men with diabetes when compared to those without diabetes [4].

ED may occur 10-15 years earlier in men with diabetes [1, 2]. Moreover, ED is more severe $[1,3]$ and less responsive to oral drugs $[5,6]$ in diabetes, leading to reduced quality of life $[7,8]$.

The proposed mechanisms of ED in patients with diabetes are represented by vasculopathy, neuropathy, visceral adiposity, insulin resistance, and testosterone deficiency. On the other hand, macrovascular disease in diabetes corresponds to the atherosclerotic damage in the blood vessels, which limits blood flow to the penis. Many of the diabetes related cardiovascular risk factors contribute to the genesis of arterial insufficiency in penis [10,11]: Above all pathophysiological changes ultimately lead to vasculogenic ED [9].

In diabetes, persistent hyperglycemia initiates anatomical and functional abnormalities that cause endothelial dysfunction leading to ED and other atherosclerosis disorders [12]. Thus, some argued that detection of ED due penile vascular atherosclerosis may be taken the sentinel event that require rigorous attempts to detect coronary artery disease (CAD) in patients with diabetes but do not have any symptom of ischemic heart disease [13]. Several hypotheses 
attempted to describe the process of endothelial dysfunction and development of ED in diabetes. In this situation decreased bioavailability of nitric oxide (NO) causes decreased relaxation of penile corpora cavernosa muscular relaxation associated with endothelial dysfunction. Advanced glycation end (AGE) products accumulation, increased reactive oxygen species (ROS) in the circulation contribute to reduce the bioavailability of NO. Impairment of both the endothelial and neural NOs and the altered vasoconstriction \& relaxation pathway is likely to favor increased penile vasculature constriction [13, 14]. In a study Esposito et al [15] found a high level of endothelial microparticles in the circulation of men with ED than men without it.

Vitamin D is important hormone of bone metabolism that contributes to maintaining the skeletal strength. However, the ubiquitous distribution of vitamin $\mathrm{D}$ receptors suggests potential for widespread effects, that has led to new research exploring the effects of vitamin D on a variety of tissues [16]. The vitamin D receptors which help present on endothelium have recently been identified to take part in modulating its function [16, 17]. An association of low levels of serum vitamin $\mathrm{D}$ with increased coronary arterial calcification has been reported in observational studies [18]. Similarly, exposure to higher levels of vitamin D may increase the chances of arterial calcification [19]. Experimental studies found improvement in cardiac function with optimal serum vitamin D status, even with supplementation in insufficiency [20].

As both ED and VDD are significant problems among men with type 2 diabetes, the study aimed to determine whether VDD is independently associated with ED in diabetes and thereby generate evidence for developing an appropriate clinical approach, research, and interventions.

\section{Materials and Methods}

\subsection{Study Design and Population}

The nested case-control study was conducted in eight diabetes care centers, one from each of the eight administrative divisions of Bangladesh recruiting 2860 patients with T2DM who had the diagnosis of ED (aging between 30 to 69 years) from July 2018 to August 2019.

After receiving the serum vitamin D reports, the respondents were grouped into the case (those had serum vitamin D level $<30 \mathrm{ng} / \mathrm{mL}$ ) and control (those had serum vitamin D level $>30 \mathrm{ng} / \mathrm{mL}$ ). Thus, 2315 (80.94\%) of the participants were cases and 545 (19.06\%) were controls.

Before the commencement the research protocol obtained ethical clearance from the Institutional Review Board of Bangabandhu Sheikh Mujib Medical University (BSMMU) prior to the commencement.

\subsection{Inclusion and Exclusion Criteria}

The study included adult men with documented type 2 diabetes for at least 2 years. Men having any medical conditions that could affect vitamin D metabolism including metabolic bone diseases such as osteoporosis, liver disease, kidney diseases, hyperparathyroidism, tuberculosis, granulomatous disease, lymphomas or hyperthyroidism, malabsorption resulting from celiac disease, Crohn's disease, and bypass were excluded. Men who were taking calcium and or vitamin D supplements, were not included in the study [21].

\subsection{Biochemical Measurements}

A skilled laboratory technician collected morning fasting $10 \mathrm{ml}$ venous blood from the respondent in a disposable syringe for the assay of serum $25(\mathrm{OH}) \mathrm{D}, \mathrm{HbA} 1 \mathrm{C}$, and lipid profile. The blood samples were centrifuged at $2000 \mathrm{rpm}$ for 15 minutes and serum was separated following that. The collected serum samples have been kept frozen at $-80^{\circ} \mathrm{C}$ until further lab analysis. Serum vitamin D assay was done by using Chromsystems reagent kit on the Waters HPLC 2695 which allowed the main metabolites of vitamin D3 and D2 to be determined in a simultaneous chromatographic manner by using a fully validated, modified highperformance liquid chromatography (HPLC) method [22]. The intra- and inter-assay coefficients of variation $(\mathrm{CVs})$ were $2.6 \%$ and $4.8 \%$, respectively. Vitamin D status were categorized into three groups; Vitamin D insufficiency 25(OH)D $<20 \mathrm{ng} / \mathrm{mL}$; vitamin D deficiency - serum $25(\mathrm{OH}) \mathrm{D}<30 \mathrm{ng} / \mathrm{mL}$ and vitamin $\mathrm{D}$ sufficiency -serum $25(\mathrm{OH}) \mathrm{D} \geq 30 \mathrm{ng} / \mathrm{mL}$.

\subsection{Data Collection}

Socio-demographic, personal and family information were collected by face-to-face interview by well-trained research physicians and disease-specific data were recorded from the patients' record book. The status of physical activity was classified as sedentary (such as doing household activities most of the time or a little walking outside), moderate activity (i,e. regular jogging, brisk walking, or regular swimming) and vigorous activity which causes sweating or rapid breathing (like heavy lifting, aerobic exercises, or regular fast bicycling). The participants were asked about their intentional or unintentional exposure to sun during week days and weekend (times spent outdoor at a stretch for at least 30 minutes keeping more than $18 \%$ of the body exposed to sunlight) and the use of sunscreen. Measurement of height (centimeters) and body weight (kilograms) in light clothing were taken using a standard scale after the interview. The body mass index (BMI) was then calculated by dividing the weight (in kilograms) by height (in square meters). Overweight and obesity were defined according to the World Health Organization (WHO) definition for the South East Asian population. The subjects were considered overweight when BMI was $23.0-27.4 \mathrm{Kg} / \mathrm{M}^{2}$, and the subjects were defined as obese when BMI was $>27.5$ $\mathrm{Kg} / \mathrm{M}^{2}$ [24]. After confirming rest for at least 5 minutes, the blood pressure of the T2DM man was measured. The WHO hypertension criteria were followed to categorize the patients; hypertension would be the diagnosis if blood pressure $\geq 140 / 90$ $\mathrm{mmHg}$ [25]. 
To evaluate sexual function, the validated Bengali version of International Index of Erectile Function (IIEF) was used. It comprised 6 items on erectile function domain. Based on a 5point Likert scale, responses fall in 1 to 30 score; a lower score indicating relatively worser erectile functional status with a cut off of $<26$ for ED. The patter of erectile functional status is given as mild ED (EF score ranging from 17-25), moderate ED (EF score ranging from 11-16) and severe ED (EF score ranging from 6-10) and no ED (EF score ranging from 26-30) [26].

\subsection{Statistical Analysis}

All collected data were entered and analyzed by using statical package for social science ( $\mathrm{v} 24$ ). To assess the association between independent variables (i.e., vitamin D levels) the chi-square test was done. The blood pressure records, glycemic status (HbA1C), BMI, WHR, sun exposure, tobacco consumption, duration of diabetes etc. were divided into equal groups. A multivariate analysis was also done by developing models to determine the association of vitamin D status and ED in DM.

\section{Results}

Table 1 demonstrates the distribution of the base line characteristics of participating type diabetes patients with ED. In total, 2315 (80.94\%) were cases with VDD and $545(19.06 \%)$ were control with normal vitamin D level. The mean age of the cases was $52( \pm 9.8)$ and of control, $51( \pm 10.2)$ years. About $1167(50.41 \%)$ of cases and 246 $(45.14 \%)$ of control had secondary and higher secondary level education. Most of the participants [1204 (52.05\%) of cases and $323(59.28 \%)$ of control] came from rural areas. The highest number of participants $[81.14 \%$ of cases and $79.81 \%$ of cases] earned 40,000 to 119,000 BDT [500 t0 1500 USD] monthly. Around 23.59\% (546) of cases and $19.27 \%(105)$ of control were smoker; $28.12 \%$ (651) of cases $22.75 \%$ (124) of control were non-smoke tobacco consumer. About $73.17 \%$ (1694) of cases and $73.58 \%$ (401) of control were of a sedentary life style. Few patients $[1.12 \%$ of cases and $0.55 \%$ of controls] had the history of sunscreen use.

Table 1. Baseline characteristics of the respondents $(n=2860)$.

\begin{tabular}{llll}
\hline & \multicolumn{2}{l}{ Frequency $\mathbf{( \% )}$} & \\
\cline { 2 - 3 } Variable & $\begin{array}{l}\text { Case 2315 } \\
\mathbf{( 8 0 . 9 4 \% )}\end{array}$ & $\begin{array}{l}\text { Control 545 } \\
\mathbf{( 1 9 . 0 6 \% )}\end{array}$ & \\
\hline Age (years) & & & \\
$<40$ & $192(8.29)$ & $41(7.52)$ & \\
$40-49$ & $807(34.86)$ & $189(34.68)$ & .002 \\
$50-59$ & $1027(44.36)$ & $223(40.91)$ & \\
$60-69$ & $289(12.49)$ & $92(16.88)$ & \\
Mean & $52 \pm 9.8$ & $51 \pm 10.2$ & \\
Education & & & \\
Illiterate & $102(4.41)$ & $23(4.22)$ & \\
Primary & $571(24.67)$ & $105(19.27)$ & \\
Secondary \& Higher Secondary & $1167(50.41)$ & $246(45.14)$ & .006 \\
Graduate & $419(18.09)$ & $159(29.17)$ & \\
Postgraduate & $56(2.42)$ & $12(2.20)$ & \\
\hline
\end{tabular}

\begin{tabular}{llll}
\hline \multirow{2}{*}{ Variable } & \multicolumn{2}{l}{ Frequency (\%) } & \\
\cline { 2 - 3 } & $\begin{array}{l}\text { Case 2315 } \\
(\mathbf{8 0 . 9 4 \% )}\end{array}$ & $\begin{array}{l}\text { Control 545 } \\
\mathbf{( 1 9 . 0 6 \% )}\end{array}$ & \\
\hline Residence & & & \\
Rural & $1204(52.05)$ & $323(59.28)$ & $<.001$ \\
Urban & $1111(48.95)$ & $222(40.72)$ & \\
Monthly Family Income (In Thousands BDT) & & \\
$<40$ & $177(7.65)$ & $34(6.29)$ & \\
$40-79$ & $948(40.95)$ & $203(37.24)$ & \\
$80-119$ & $935(40.39)$ & $232(42.57)$ & .043 \\
$>120$ & $255(11.06)$ & $92(16.88)$ & \\
Smoking Tobacco & & & \\
Current smoker & $546(23.59)$ & $105(19.27)$ & \\
Quitted & $161(6.95)$ & $31(5.69)$ & .004 \\
Nonsmoker & $1608(69.46)$ & $409(75.05)$ & \\
Non-smoke Tobacco consumption & & & \\
Consumer & $651(28.12)$ & $124(22.75)$ & .002 \\
Non-consumer & $1664(71.88)$ & $421(77.25)$ & \\
Physical Activity level & & & \\
Sedentary/ Mild & $1694(73.17)$ & $401(73.58)$ & \\
Moderate & $476(20.56)$ & $123(22.57)$ & .000 \\
Vigorous & $145(6.26)$ & $21(3.85)$ & \\
History Regular Sun Exposure & & & \\
Present & $26(1.12)$ & $3(0.55)$ & $<.001$ \\
\hline
\end{tabular}

Table 1 demonstrates the distribution of the base line characteristics of participating type diabetes patients with ED. In total, 2315 (80.94\%) were cases with VDD and $545(19.06 \%)$ were control with normal vitamin D level. The mean age of the cases was $52( \pm 9.8)$ and of control, $51( \pm 10.2)$ years. About 1167 $(50.41 \%)$ of cases and $246(45.14 \%)$ of control had secondary and higher secondary level education. Most of the participants [1204 (52.05\%) of cases and $323(59.28 \%)$ of control] came from rural areas. The highest number of participants [ $81.14 \%$ of cases and $79.81 \%$ of cases] earned 40,000 to 119,000 BDT [500 t0 1500 USD] monthly. Around 23.59\% (546) of cases and $19.27 \%$ (105) of control were smoker; $28.12 \%$ (651) of cases $22.75 \%$ (124) of control were non-smoke tobacco consumer. About $73.17 \%$ (1694) of cases and $73.58 \%$ (401) of control were of a sedentary life style. Few patients [1.12\% of cases and $0.55 \%$ of controls] had the history of sunscreen use.

Table 2 shows the clinical and biochemical parameters of the participants. Almost all the participants were overweight or obese [mean BMI- 26.58 \pm 6.7 and 24.83 $\pm 5.3, \mathrm{p}=.002$; WHR $0.95 \pm 0.08$ and $0.91 \pm 0.05, \mathrm{p}=<.001$ for cases and control respectively]. Around half of the patients were hypertensive [ $51.07 \%$ cases and $50.35 \%$ controls, $\mathrm{p}=.004$ ]. Lipid disorders were also present $[62.11 \%$ cases and $59.87 \%$ controls, $\mathrm{p}=.008$ ]

Table 2. Clinical Variables of the participants $(n=2860)$.

\begin{tabular}{llll}
\hline \multirow{2}{*}{ Variable } & \multicolumn{2}{l}{ Frequency (\%) } & \multirow{2}{*}{ P value } \\
\cline { 2 - 3 } & $\begin{array}{l}\text { Case 2315 } \\
\mathbf{( 8 0 . 9 4 \% )}\end{array}$ & $\begin{array}{l}\text { Control 545 } \\
\mathbf{( 1 9 . 0 6 \% )}\end{array}$ & \\
\hline Mean BMI (Kg/M $\left.{ }^{2}\right)$ & $26.58 \pm 6.7$ & $24.83 \pm 5.3$ & .002 \\
Mean waist-hip ratio (WHR) & $0.95 \pm 0.08$ & $0.91 \pm 0.05$ & $<.001$ \\
Mean HbA1C (\%) & $9.28 \pm 2.6$ & $8.65 \pm 2.5$ & $<0.001$ \\
Hypertensives & $1182(51.07)$ & $274(50.35)$ & .004 \\
Dyslipidemic & $1437(62.11)$ & $326(59.85)$ & .008 \\
\hline
\end{tabular}

Table 2 shows the clinical and biochemical parameters of the participants. Almost all the participants were overweight or obese [mean BMI- 26.58 \pm 6.7 and $24.83 \pm 5.3, \mathrm{p}=.002$; WHR $0.95 \pm 0.08$ and $0.91 \pm 0.05, \mathrm{p}=<.001$ for cases and control respectively]. Around half of the patients were hypertensive [51.07\% cases and $50.35 \%$ controls, $\mathrm{p}=.004]$. Lipid disorders were also present [ $62.11 \%$ cases and $59.87 \%$ controls, $\mathrm{p}=.008]$ 
Tables 3 shows the serum vitamin D status of patients with type 2 diabetes. Among the controls, vitamin sufficiency, insufficiency and deficiency are $22.20 \%, 61.28 \%$ and $16.51 \%$ respectably. About $18.39 \%, 62.16$ and $18.6 \%$ of the type 2 diabetes patients with ED had vitamin D deficiency, insufficiency and sufficiency respectably $[p<.001]$.

Table 3. Distribution of the participants according to serum vitamin D levels $(n=2860)$.

\begin{tabular}{llll}
\hline Variable & \multicolumn{2}{l}{ Frequency (\%) } & \\
\cline { 2 - 3 } & $\begin{array}{l}\text { Case 2315 } \\
(\mathbf{8 0 . 9 4 \% )}\end{array}$ & $\begin{array}{l}\text { Control 545 } \\
\mathbf{( 1 9 . 0 6 \% )}\end{array}$ & \\
\hline Serum Vitamin D & & & \\
Deficiency $(<20 \mathrm{ng} / \mathrm{mL})$ & $425(18.39)$ & $90(16.51)$ & \\
Insufficient $(20-30 \mathrm{ng} / \mathrm{mL})$ & $1439(62.16)$ & $334(61.28)$ & $<.001$ \\
Sufficient $(>30 \mathrm{ng} / \mathrm{mL})$ & $431(18.6)$ & $121(22.20)$ & \\
\hline
\end{tabular}

Tables 3 shows the serum vitamin D status of patients with type 2 diabetes. Among the controls, vitamin sufficiency, insufficiency and deficiency are $22.20 \%, 61.28 \%$ and $16.51 \%$ respectably. About $18.39 \%, 62.16$ and $18.6 \%$ of the type 2 diabetes patients with ED had vitamin D deficiency, insufficiency and sufficiency respectably $[\mathrm{p}<.001]$.

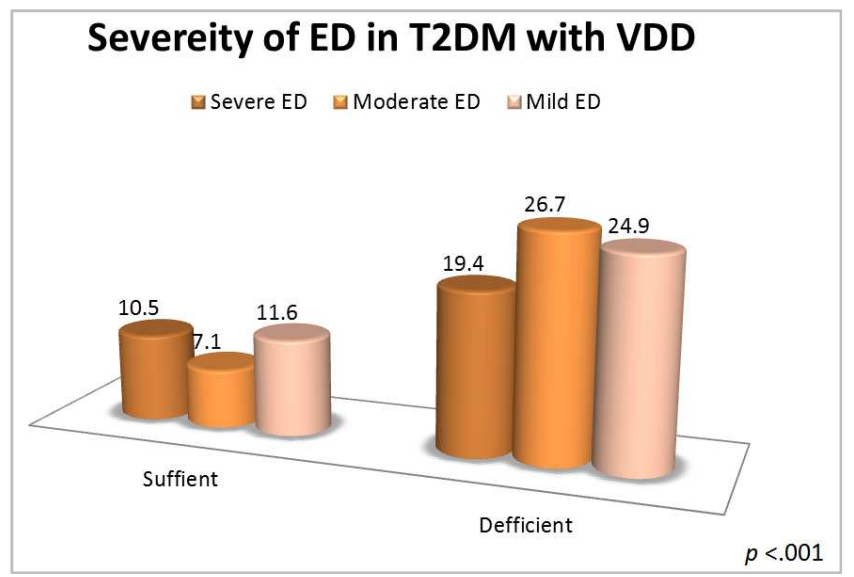

Figure 1. Shows the stages of ED of the participants. The vitamin $D$ deficient T2DM subjects were at the highest proportion of moderate ED (26.7\% and 7.1\%). These are similar for severe and mild ED [24.9; 11.6 and $19.4 ; 10.5]$ with a $p$ value of $<.001$.

Figure 1 depicts the stages of ED of the participants. The T2DM patients with VDD comprised the largest proportion of moderate ED (26.7\% and $7.1 \%)$. The distribution is almost similar for severe and mild ED [24.9; 11.6 and 19.4; 10.5] with a $p$ value of $<.001$.

Table 4 shows multiple logistic regressions which was applied to determine the factor relating to ED in T2DM adjusting for all possible confounders and cofactors. Age has been from the model due to co-linearity with age of onset and duration of diabetes. VDD [OR 2.83, CI 2.36, 3.97], BMI [OR 1.12, CI. 08, 1.42], WHR [OR 2.47, CI 1.88, 2.91], smoking tobacco [OR 1.94 CI 1.65, 2.36], smokeless tobacco consumption [OR 1.31, CI. 98, 1.57) and duration of DM increased [OR 1.51, CI 1.28, 1.87] probability of ED, whereas educational attainment (OR 0.91, CI 0.71, 0.98) and sun exposure (OR $0.85 \mathrm{CI} 0.68,1.32$ ) showed to have protective impact on ED.
Table 4. Multiple logistic regression of erectile diabetes and vitamin D status adjusting for possible confounders.

\begin{tabular}{lll}
\hline & OR $(\mathbf{9 5 \%} \mathbf{C I})$ & P \\
\hline VDD & $2.83(2.36,3.97)$ & 0.001 \\
BMI & $1.12(.08,1.42)$ & 0.006 \\
WHR & $2.47(1.88,2.91)$ & 0.001 \\
Sun Exposure & $0.85(0.68,1.32)$ & 0.03 \\
Education & $0.91(0.71,0.98)$ & 0.060 \\
Monthly Income & $1.18(0.99,1.30)$ & 0.001 \\
Smoking Tobacco & $1.94(1.65,2.36)$ & 0.000 \\
Smokeless Tobacco Consumption & $1.31(.98,1.87)$ & 0.005 \\
Duration of DM & $1.51(1.28,1.99)$ & 0.000 \\
Nagelkerke R Square & 0.067 & \\
\hline
\end{tabular}

Table 4 shows multiple logistic regressions were applied to determine the factor relating to ED in T2DM adjusting for all possible confounders and cofactors. VDD [OR 2.83, CI 2.36, 3.97], BMI [OR 1.12, CI. 08, 1.42], WHR [OR 2.47, CI 1.88, 2.91], smoking tobacco [OR 1.94 CI 1.65, 2.36], smokeless tobacco consumption [OR 1.31, CI. 98, 1.57) and duration of DM increased [OR 1.51, CI 1.28, 1.87] probability of ED, whereas educational attainment (OR 0.91, CI 0.71, 0.98) and sun exposure (OR 0.85 CI0.68, 1.32) showed to have protective impact on ED.

\section{Discussion}

This study revealed that the men with T2DM VDD (serum $25(\mathrm{OH}) \mathrm{D}<30 \mathrm{ng} / \mathrm{mL})$ are found to have 2.83 times more likelihood to suffer from ED than the T2DM patients with adequate vitamin $D$ status (serum $25(\mathrm{OH}) \mathrm{D} \geq 30 \mathrm{ng} / \mathrm{mL}$ ). Several other studies showed correlation between low $25(\mathrm{OH}) \mathrm{D}$ plasma levels and ED $[27,28]$ and particularly in patients with poor glycemic control and longer diabetes duration [29]. Several studies showed an inverse association similar to what was found in the present study [29].

The study determined and staged erectile function of men with T2DM. The vitamin D deficient T2DM patients were mostly in the moderate ED (26.7\%). The patients with severe and mild ED, the vitamin deficient T2DM patients had higher frequency [24.9; 11.6 and $19.4 ; 10.5]$ with a $p$ value of $<.001$.

One study reported lower serum vitamin $\mathrm{D}$ in atherogenic ED. These patients had significantly low IIEF scores, lower peak systolic velocity in penile duplex study measurements as well [32], Another study reported relation of hypovitaminosis D with ED [21, 22] hypothesizing in a review that hypovitaminosis $\mathrm{D}$ might be the pivotal pathophysiological event in causing ED in DM [23] that warrants further vigorous researches. A good number studies demonstrated the relationship of VDD with ED and the probable mechanisms were depicted as well. To date, DM is one of the well-established risk factors of atherosclerotic cardiovascular diseases including ED [30], as men with DM may have 3 times more likelihood to be affected by ED [34]. This association may be imparted by VDD modified pancreatic beta cell dysfunction leading insulin secretory deficiency and incident T2DM [31, 33-36].

It is now established that men with ED have an increased risk of endothelial dysfunction [37], and adequate serum vitamin D may improve endothelial functional status [38]. The mechanism of ED in low vitamin D levels may be due to reduced synthesis of nitric oxide. Secretion of nitric oxide is 
needed for relaxation of the smooth muscles of the corpora cavernosa and subsequently penile erection, and vitamin D may be a regulator of endothelial nitric oxide synthase [29]. Vitamin D directly protects endothelial cells from oxidative stress as well [39].

The study found $74.16 \%$ of cases and $70.28 \%$ of controls had VDD $(\leq 20 \mathrm{ng} / \mathrm{mL})(\mathrm{p}<.001)$, which appears to be consistent with previous studies within Saudi Arabia. Naeem et al. showed that the mean vitamin D levels were $32 \mathrm{ng} / \mathrm{mL}$ and $23 \mathrm{ng} / \mathrm{mL}$ among Saudi males and females, respectively [40]. Alsuwaida et al. described similarly findings found in the nationwide Saudi Arabian survey [41].

\section{Conclusion}

The patients with diabetes have high rate of VDD. There is inverse relationship between serum vitamin D status and ED among men with T2DM. Obesity, tobacco consumption, physical inactivity and duration of diabetes contribute in causing ED. Sun exposure and better education were found to be protective among them. So, it can be hyposensitized that patients with diabetes may consider maintaining vitamin D sufficiency by adequate sun exposure or supplementation with the hope to lessen the incidence of ED.

\section{Conflicts of Interest}

There are no conflicts of interest.

\section{Acknowledgements}

The authors are grateful to BSMMU for the research grant and to all type 2 diabetes patients who participated in the study.

\section{References}

[1] Jumani DK, Patil O. Erectile dysfunction in diabetes mellitus: A review. J Diabetol 2020; 11: 1-7.

[2] Thorve VS, Kshirsagar AD, Vyawahare NS, Joshi VS, Ingale KG, Mohite RJ. Diabetes-induced erectile dysfunction: epidemiology, pathophysiology and management. J Diabetes Complications. 2011; 25 (2): 129-136.

[3] Feldman HA, Goldstein I, Hatzichristou DG, Krane RJ, McKinlay JB. Impotence and its medical and psychosocial correlates: results of the Massachusetts Male Aging Study. J Urol. 1994; 151 (1): 54-61.

[4] Bahar A, Elyasi F, Moosazadeh M, Afradi G, Kashi Z. Sexual dysfunction in men with type II diabetes. Caspian J Intern Med. 2020; 11 (3): 295-303. doi: 10.22088/cjim.11.3.295.

[5] Alwaal, AA, Mohannad B, Nathan KJ, Snoad, B (2020). Sexual Health Inventory for Men Questionnaire as a Screening Method for Erectile Dysfunction in a General Urology Clinic. Sexual medicine. 10.1016/j.esxm.2020.08.002.

[6] Corona G, Giorda CB, Cucinotta D, Guida P, Nada E; Gruppo di studio SUBITO-DE. The SUBITO-DE study: sexual dysfunction in newly diagnosed type 2 diabetes male patients. J Endocrinol Invest. 2013; 36 (10): 864-868.

[7] Penson DF, Latini DM, Lubeck DP, Wallace KL, Henning JM, Lue TF; Comprehensive Evaluation of Erectile Dysfunction (ExCEED) database. Do impotent men with diabetes have more severe erectile dysfunction and worse quality of life than the general population of impotent patients? Results from the Exploratory Comprehensive Evaluation of Erectile Dysfunction (ExCEED) database. Diabetes Care. 2003; 26 (4): 1093-1099.

[8] DeBerardis G, Franciosi M, Belfiglio M, et al; Quality of Care and Outcomes in Type 2 Diabetes (QuED) Study Group. Erectile dysfunction and quality of life in type 2 diabetic patients: a serious problem too often overlooked. Diabetes Care. 2002; 25 (2): 284-291.

[9] Esposito K, Giugliano F, Martedì E, Martedì E, Feola G, Marfella R, D'Armiento M, Giugliano D. High proportions of erectile dysfunction in men with the metabolic syndrome. Diabetes Care. 2005; 28 (5): 1201-1203.

[10] Sahin, MO, Sen V, Gunduz, G, Ucer, O. (2020). Effect of smoking cessation on sexual functions in men aged 30 to 60 years. International braz j urol, 46 (4), 642-648. Epub June 01, 2020 .

[11] Giuliano FA, Leriche A, Jaudinot EO, de Gendre AS. Prevalence of erectile dysfunction among 7689 patients with diabetes or hypertension, or both. Urology. 2004; 64 (6): 1196-1201.

[12] Guay AT. ED2: Erectile dysfunction=endothelial dysfunction. Endocrinol Metab Clin North Am. 2007; 36 (2): 453-463.

[13] Cheitlin MD. Erectile dysfunction: the earliest sign of generalized vascular disease? J Am Coll Cardiol. 2004; 43 (2): $185-186$.

[14] Malavige LS, Levy JC. Erectile dysfunction in diabetes mellitus. J Sex Med. 2009; 6 (5): 1232-1247.

[15] Esposito K, Ciotola M, Giugliano F, et al. Endothelial microparticles correlate with erectile dysfunction in diabetic men. Int J Impot Res. 2007; 19 (2): 161-166.

[16] Matthieu Halfon, Olivier Phan, Daniel Teta, "Vitamin D: A Review on Its Effects on Muscle Strength, the Risk of Fall, and Frailty", BioMed Research International, vol. 2015, Article ID 953241, 11 pages, 2015. https://doi.org/10.1155/2015/953241.

[17] Al-Nozha MM; Abdullah M, Arafah MR, Al-Maatouq MA, Al-Marzouki K, Al-Khadra A, Nouh MS, Al-Harthi SS, AlShahid MS, Al-Mobeireek A. Hypertension in Saudi Arabia. Saudi Med. J. 2007, 28, 77-84.

[18] Nitta, K. Impact of vitamin D metabolism on cardiovascular disease. Int. J. Clin. Med. 2011, 2.

[19] Wang TJ, Pencina MJ, Booth SL, Jacques PF, Ingelsson E, Lanier K, Benjamin EJ, D'Agostino RB, Wolf M, Vasan RS, Vitamin D deficiency and risk of cardiovascular disease. Circulation 2008, 117, 503-511.

[20] Schöttker B, Jorde R, Peasey A, Thorand B, Jansen EH, deGroot L, Streppel M, Gardiner J, Ordóñez-Mena JM, Perna L. Vitamin D and mortality: meta-analysis of individual participant data from a large consortium of cohort studies from Europe and the United States. Br. Med. J. 2014, 348, g3656. 
[21] Holick, MF. Vitamin D deficiency. N Engl J Med. 2007, 357 , 266-281.

[22] Al-Nozha MM, Arafah MR, Al-Mazrou YY, Al-Maatouq MA, Khan NB, Khalil MZ, Al-Khadra AH, Al-Marzouki K, Abdullah MA, Al-Harthi SS. Coronary artery disease in Saudia Arabia. Saudi Med. J. 2004, 25, 1165-1171.

[23] Gallagher JC, Sai AJ. Vitamin D insufficiency, deficiency, and bone health. J. Clini. Endocrinol. Metab. 2010; 95: 26302633.

[24] Wells S, Broad J, Jackson R. Alcohol consumption and its contribution to the burden of coronary heart disease in middleaged and older New Zealanders: A population-based casecontrol study. NZMJ 2004 March; 117 (1190): 1-14. URL: http://www.nzma.org.nz/journal/117-1190/793/.

[25] Shils ME, Shike M. Modern Nutrition in Health and Disease, 1st ed.; Lippincott Williams \& Wilkins: Philadelphia, PA, USA, 2006

[26] Caretta, Nicola \& Vigili de Kreutzenberg, Saula \& Valente, Umberto \& Guarneri, Gabriella \& Ferlin, Alberto \& Avogaro, Angelo \& Foresta, Carlo. Hypovitaminosis D is associated with erectile dysfunction in type 2 diabetes. Endocrine. 2016; 53. 10.1007/s12020-015-0851-z.

[27] Reis JP, vonMühlen D, Michos ED, Miller ER, Appel LJ, Araneta MR, Barrett-Connor E. Serum vitamin D, parathyroid hormone levels and carotid atherosclerosis. Atherosclerosis 2017; 585-590 (2009).

[28] Al-Tamini DJ, Ali AF. Serum $25(\mathrm{OH}) \mathrm{D}$ in diabetes mellitus type 2: relation to glycaemic control. J Clin Diagn Res 2013; 7: 2686-2688.

[29] Andrukhova O, Slavic S, Zeitz U, Riesen SC, Heppelmann MS, Ambrisko TD, Markovic M, Kuebler WM, Erben RG. Vitamin D Is a Regulator of Endothelial Nitric Oxide Synthase and Arterial Stiffness in Mice, Molecular Endocrinology, January 2004; 28 (1): 53-64, https: //doi.org/10.1210/me.2013-1252.

[30] Tousoulis D, Papageorgiou N, Androulakis E, Siasos G, Latsios G, Tentolouris K, Stefanadis C. Diabetes mellitusassociated vascular impairment: novel circulating biomarkers and therapeutic approaches. J Am Coll Cardiol 2013. 62 (2013) 667e676.
[31] Barassi A, Pezzilli R, Colpi GM, Romanelli MMC, d'Eril GVM. Serum vitamin D levels and erectile dysfunction: A systematic review and meta-analysis,. Andrologia, 2018; 51, 3.

[32] Sorenson M, Grant WB. Does vitamin D deficiency contribute to erectile dysfunction? Dermatoendocrinol 2012; 4: 2, 128-136.

[33] Selvin E, Burnett Al, Platz EA. Prevalence and risk factors for erectile $2007 \mathrm{Feb} ; 120$ (2): 151-7.

[34] Chiu KC, Chua A, Go VL, Saad MF. Hypovitaminosis D is associated with insulin resistance and beta cell dysfunction, Am. J. Clin. Nutr 2004 May; 79 (5): 820-5.

[35] Pittas AG, Lau J, Hu FB, Dawson-Hughes B. The role of vitamin $\mathrm{D}$ and calcium in type 2 diabetes. A systematic review and meta-analysis, J. Clin 2017 Jun; 92 (6): 2017-29.

[36] Song Y, Wang L, Pittas AG, Del Gobbo LC, Zhang C, Manson JE, Hu FB. Blood 25-hydroxy vitamin D levels andincident type 2 diabetes: a meta-analysis of prospective studies, Diabetes Care 2013 May; 36 (5): 1422-8. doi: 10.2337/dc12-0962.

[37] Peyton CC, Colaco MA, Kovell RC, Kim JH, Terlecki RP. Erectile dysfunction is predictive of endothelial dysfunction in a well visit population, J. Urol 2016 Apr; 195 (4 Pt 1): 104550. doi: 10.1016/j.juro.2015.11.037. Epub 2015 Nov 22.

[38] Reynolds JA, Haque S, Williamson K, Ray DW, Alexander MY, Bruce IN. Vitamin D improves endothelial dysfunction and restores myeloid angiogenic cell function via reduced CXCL-10 expression in systemic lupus erythematosus. Sci Rep. 2016 Mar 1; 6: 22341. doi: 10.1038/srep22341. PubMed PMID: 26930567; PubMed Central PMCID: PMC4772382.

[39] Uberti F, D. Lattuada, V. Morsanuto, et al., Vitamin D protects human endothelial cells from oxidative stress through the autophagic and survival path- ways, J. Clin. Endocrinol Metab 2014 Apr; 99 (4): 1367-74. doi: 10.1210/jc.2013-2103. Epub 2013 Nov 27.

[40] Naeem Z, AlMohaimeed A, Sharaf FK, Ismail H, Shaukat F, Inam SB. Vitamin D status among population of Qassim Region, Saudi Arabia. Int J Health Sci 2011; 5: 116-117.

[41] Alsuwaida, AO, Farag YM, Sayyari AAA, Mousa DH, Alhejaili FF, Al-Harib AS, Housawi AA, Mittal BV, Singh AK. Prevalence of vitamin D deficiency in Saudi adults. Saudi Med. J. 2013, 34, 814-818. 